\title{
A model for the development of genetics education programs for health professionals
}

Clara L. Gaff, PhD ${ }^{1,2}$, MaryAnne Aitken, $P h D^{3,4}$, Anna Flouris, $P h D^{3,4}$, and Sylvia A. Metcalfe, $P h D^{3,4}$

\begin{abstract}
Purpose: The need for education programs to facilitate the integration of genetics into health practice is well recognized. The inclusion of education as an aspect of genetics policy and the establishment of national bodies for genetics education extend program development beyond ad hoc programs conducted by individual practitioners. A framework for the development of an effective program is required that has a strong theoretic basis and incorporates rigorous evaluation. Methods: Relevant aspects of three theories that can inform genetics education programs are described: program logic modeling, adult learning theory, and evaluation theory. These are drawn on to develop a framework for the development and implementation of genetics education programs for health professionals and concurrent evaluation. Results: The utility of the framework is demonstrated in the development and implementation of "The Genetics File" program, a multifaceted program for general practitioners, comprising an enduring print resource and interactive workshop. The evaluation strategy developed is also documented. Conclusions: Program logic, adult learning theory, and evaluation theory together provide a useful and relevant theoretic framework for the development of genetics education programs for health professionals. Genet Med
\end{abstract} 2007:9(7):451-457.

Key Words: genetics education, family physicians, health personnel, professional education, program logic, program evaluation

The need for a genetically literate health workforce is now widely accepted. ${ }^{1-4}$ The development of such a workforce requires recognition by the health professional group that education is necessary, definition of the knowledge and skills required for competency, development and implementation of education programs, and evaluation to determine whether the education strategy has had the desired outcomes.

The first two of these steps have been widely addressed. It has long been recognized that health professionals' knowledge of genetics is limited, and this seems to remain the case..$^{5-8}$ Learning needs assessments involving family physicians/general practitioners (GPs), ${ }^{9}$ nursing professionals, ${ }^{10}$ and specialist trainees ${ }^{11}$ indicate that these professionals recognize that their skills are not sufficient and identify areas to be addressed by education programs. In parallel, competencies in genetics

From the ${ }^{1}$ Genetic Health Services Victoria, Parkville, Australia; ${ }^{2}$ Institute of Medical Genetics, Cardiff University, Heath Park, United Kingdom; ${ }^{3}$ Murdoch Childrens Research Institute, Parkville, Australia; and ${ }^{4}$ Department of Paediatrics, The University of Melbourne, Australia.

Disclosure: The authors declare no conflict of interest.

Clara Gaff, PhD, Institute of Medical Genetics, Cardiff University, Heath Park CF14 4XN, United Kingdom. E-mail: clara.gaff@ghsv.org.au.

A supplementary Appendix is available via the ArticlePlus feature at www.geneticsinmedicine. org. Please go to the July issue and click on the ArticlePlus link posted with the article in the Table of Contents to view this material.

Submitted for publication February 11, 2007.

Accepted for publication April 6, 2007.

DOI: 10.1097/GIM.0b013e3180a6eb69 for health professionals have been developed ${ }^{12,13}$ and inform the curricula of education programs for undergraduates, postgraduate trainees, and practitioners.

Meeting the education needs of professionals already in practice remains a challenge. This is the realm of Continuing Professional Development (CPD) or Continuing Medical Education. We use the acronym CPD in this article because it is particularly apt for genetics, in which the focus is not solely medical care but also psychosocial issues. Although there is a large body of literature stating the need for education of GPs and assessing attitudes, needs, and current practice of GPs, a search $^{*}$ of the available published literature suggests relatively few programs are described that aim to improve the genetic literacy of practicing health professionals ${ }^{14-22}$; only one of these is specifically for GPs. ${ }^{19,20}$ Rarely is the theoretic framework underlying a program and its evaluation made explicit. There is considerably more activity in the development of webbased, CD-ROM, and print resources than the peer-reviewed literature would indicate, ${ }^{23,24}$ and genetic specialists commonly provide education as an adjunct to their clinical or laboratory work. However, although it is not possible to judge the quality of these approaches, there is little reason to suppose

\footnotetext{
*Search methods: Conducted September 2006, CINAHL, OVID, PubMed, ERIC. Searches conducted: Genetic ${ }^{*}$ Education Program ${ }^{*}$ and Health Professional ${ }^{*}$; Genetic ${ }^{*}$ Education and Health Professional or primary care $\left({ }^{*}\right.$ is wildcard). PubMed was also searched using combinations of the terms "Genetics," "Education," "GP/Family Physician," "Theory," and "Evaluation." All searches were limited to years 1996 to 2006 and publications in English.
} 
that they have a more stringent theoretic basis to education and evaluation than published programs.

Burton and Zimmern ${ }^{25}$ highlight the crucial role of education in genetics policy and describe initiatives to strengthen education in the United Kingdom and Europe. Although the development of small ad hoc education programs is likely to remain a component of many genetic specialists' workload, the increasing emphasis on evidence-based delivery means that expectations of funded programs will, and should, be greater. Policy makers will require value for money and evidence that programs have met tangible, measurable outcomes. A framework to develop programs underpinned by evidence-based educational theory and incorporating meticulous evaluation is required. Here, we provide a theoretic approach that can be applied to the development and evaluation of any genetics education activity. We illustrate the use of this framework in the development of a multifaceted education program in genetics for GPs ("The Genetics File") and a strategy to evaluate this program. The results of the evaluation will be reported separately.

\section{A THEORETIC APPROACH}

Different aspects of the delivery of genetics education-educational approach, program development, and evaluationdraw on distinct and extensive bodies of theory. It is beyond the scope of this article to summarize each of these areas. Instead, we present a useful and versatile theoretic framework (program logic ${ }^{26}$ ) for the overall development of a program. A broader overview of evaluation theory is provided, because a single program may require several different phases of evaluation. We begin with a discussion of adult learning theory, which underpins the educational component.

\section{Adult learning theory}

The design of CPD programs has progressed considerably beyond the assumption (common before the 1970s) that transmission of research findings alone is sufficient to influence a change in GP behavior. That approach exemplifies traditional education methods, which are characterized by teacher-centeredness, a focus on content and students adopting a passive role. ${ }^{27}$ Drawn from "constructivism," adult learning theory (andragogy) proposes that "as people mature their self concept moves from dependence toward self-direction, an accumulating body of experience serves as a resource for their learning. . . they seek knowledge for immediate application in solving problems." 28 This description is obviously applicable to health professionals, who are skilled, experienced learners with complex and unique learning needs and whose work requires a commitment to continuous relearning for immediate application. ${ }^{29}$ This is an aspect of "lifelong learning" and may occur incidentally through experience or as the result of a planned activity.

For a planned education program (e.g., a CPD activity) to be effective, learners bring or develop skills that enable them to learn. The program must provide conditions that are respon- sive to the learners and enable them to learn best. These are in essence two sides of the same coin and relate to the overlapping principles of adult learning summarized by Brookfield ${ }^{30}$ and Knowles: ${ }^{31}$ (1) Learning is self-directed, and adults should recognize a need for learning (intrinsic motivation) and be involved in the planning and evaluation of their instruction; (2) experience (including mistakes) provides a resource for learning; (3) adults are most interested in topics that are relevant to their work, with learning involving critical reflection and reflective practice in their own work or life context; and (4) adult learning is problem-centered rather than content-oriented, with learners redeveloping personal learning strategies. These principles provide a basis for education program development. This implies that an effective program will involve the learner in planning the program; focus as much on the learning process as the content being taught; use a range of teaching strategies, particularly methods that are experiential, interactive, and encourage the learner to reflect on past experience; build their new learning into conceptual frameworks; and consider the future applicability of the new skills or information. The conditions for learning and skills required by adult learners are discussed more fully by Hinchcliff. ${ }^{32}$

\section{Program logic modeling}

A program logic model is a tool to assist with "program design, program planning, and program evaluation." ${ }^{26}$ Simply, it is a theory of how a program should work. ${ }^{33}$ It identifies the program goals and describes the components of the program, including how the short- and long-term outcomes will be achieved $^{26}$ and the assumptions made about the relationship between the activities and the benefits the program is expected to produce..$^{34}$ Consequently, the strengths and weaknesses of a program, including unfounded assumptions, may be identified. A program logic, then, forms the basis not only of program design but also assists in the development of hypotheses that may be tested and informs the development of an evaluation strategy. This is elaborated on later in the Evaluation Theory and Strategy section. Of course, the use of program logic models is not limited to education programs. They have been used extensively (e.g., in health and social programs) and are well suited to the development and evaluation of new programs in genetics, be they clinical or educational.

There are many different ways to portray a program logic model, for example, in linear, matrix, table, or narrative form. ${ }^{26,35}$ To build a model for a new program, those closely associated with the design and implementation of the program define the need or problem the program is to address. A "hierarchy of outcomes" may then be used to define the activities or program to be conducted, its outputs, and expected outcomes. A generic example of a hierarchy of outcomes for an education program is given in Figure 1. Alternatively, this could be documented as a series of testable hypotheses, for example, if the health professional participates in the education program, then he/she will have an increased awareness of the relevance of genetics. 


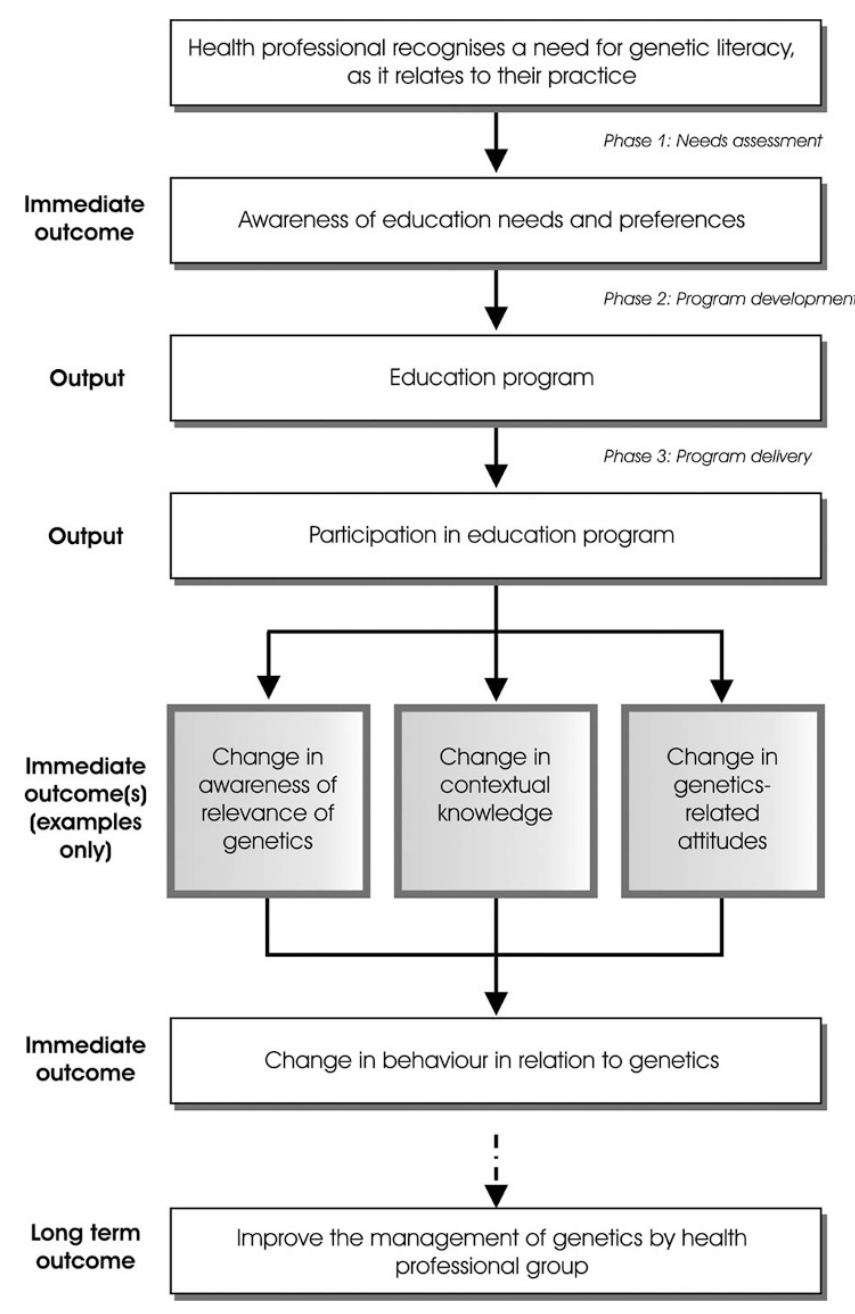

Fig. 1. An example of a hierarchy of outcomes that may be generally applied to a genetics education program.

A basic program logic model can be expanded to include all the action steps necessary to produce the outputs, resources, and relationships required and the external factors influencing the success of the program. Program logic models are often simplistic in the beginning and are elaborated as the program is developed and conducted. For a comprehensive discussion and presentation of complete program logic models, we recommend Wholey et al. ${ }^{35}$ and Funnell. ${ }^{26}$

\section{EVALUATION THEORY AND STRATEGY}

Evaluation is a familiar term: We constantly "evaluate" or judge the value of objects, events, or courses of action. These evaluations are usually informal, and the outcome-a judgment-is commonly given without describing the process by which it was reached or what comparisons have been made. In the context of evidence-based practice, evaluation refers to a more precise and complex process. Systematic evaluation requires the planned activity (i.e., education program) to be clearly delineated with expected, measurable outcomes; the purpose of the evaluation to be stated; the criteria by which the program is to be judged to be defined before the operation of the program; and the collection and analysis of empiric data to determine whether these criteria have been met. ${ }^{36}$ Although most of the genetics education programs described previously incorporate an element of evaluation, ${ }^{15-22}$ few seem to have taken the rigorous, systematic approach described above.

Because the hypotheses in the program logic model are testable, ${ }^{26}$ the model naturally lends itself to the development of an evaluation strategy and the application of scientific methods. The model describes assumptions that may need to be tested, intended activities that may need to be validated, and impacts that must be measured. As the life cycle of a program moves through the phases of development, implementation, and decline/replacement/reinvigoration, ${ }^{37}$ evaluation should occur as a central activity to determine the success (or otherwise) of that phase and to inform subsequent developments. Each phase, then, should be subject to a distinct evaluation process with different evaluation questions and methods. Therefore, there are corresponding stages in an evaluation cycle, for example, formative, process, and summative/outcome. Formative evaluation can comprise identification of the problem (e.g., by needs assessment) and/or assessment of the program design (the program logic) and its activity and piloting. Process evaluation is conducted while the program is operating and aims to verify that the program is running as intended and may result in incremental change during operation. Summative or outcome evaluation investigates the short-term, intermediate, or long-term effect of the program. Each of these requires the aims of the program to be clearly elucidated, and, in the case of summative evaluation, outcome measures related to the program aim must have been specified at the outset.

Determining the desired outcomes may not be as straightforward. Programs and evaluations may have multiple stakeholders, such as the educators, the funding bodies, and the target group's professional association. Each of these may have different priorities or views of what constitutes a successful program or evaluation.

It is worth noting the difference between evaluation and quality assessment activities: the latter involves gathering data relating to the continuing quality of an established program rather than determination of the value of the program. Evaluation is also distinct from assessment, which ascertains an individual's performance within the program.

\section{THEORY IN PRACTICE: THE GENETICS FILE}

"The Genetics File" is a CPD education program that has the long-term aim of improving GPs' management of families with, or at risk of, inherited conditions and demonstrates the practical application of the theoretic approach described above. The generic program logic presented in Figure 1 is used as a guide as we describe the way theory has informed different phases of the program and the lessons that have been learned. 


\section{Awareness and assessment of need}

Consistent with adult learning theory, which suggests that adults must feel a need for education, be involved in its planning and evaluation, and learn best when the topic is directly relevant or of immediate value, the first steps of the program were to determine whether GPs in Victoria recognized a need for greater genetic literacy and to identify the education needs and preferences of this group. This work has been published and will not be reiterated in detail here. ${ }^{8,9}$ In summary, GPs identified the following areas as priorities for education: talking with families about genetics, familial cancers, hemochromatosis, adult-onset neurologic conditions, testing during pregnancy, Down syndrome, thalassemia disorders, fragile $\mathrm{X}$ syndrome, and cystic fibrosis. The education strategy favored by the participating GPs was "enduring" materials in print, Internet, or CD-ROM formats. These results of the needs assessment informed the program development.

\section{Program development}

The strategy adopted for development of the program, comprising both a written resource and workshop, is provided in Figure 2. This is in effect an elaboration of the "Program De-

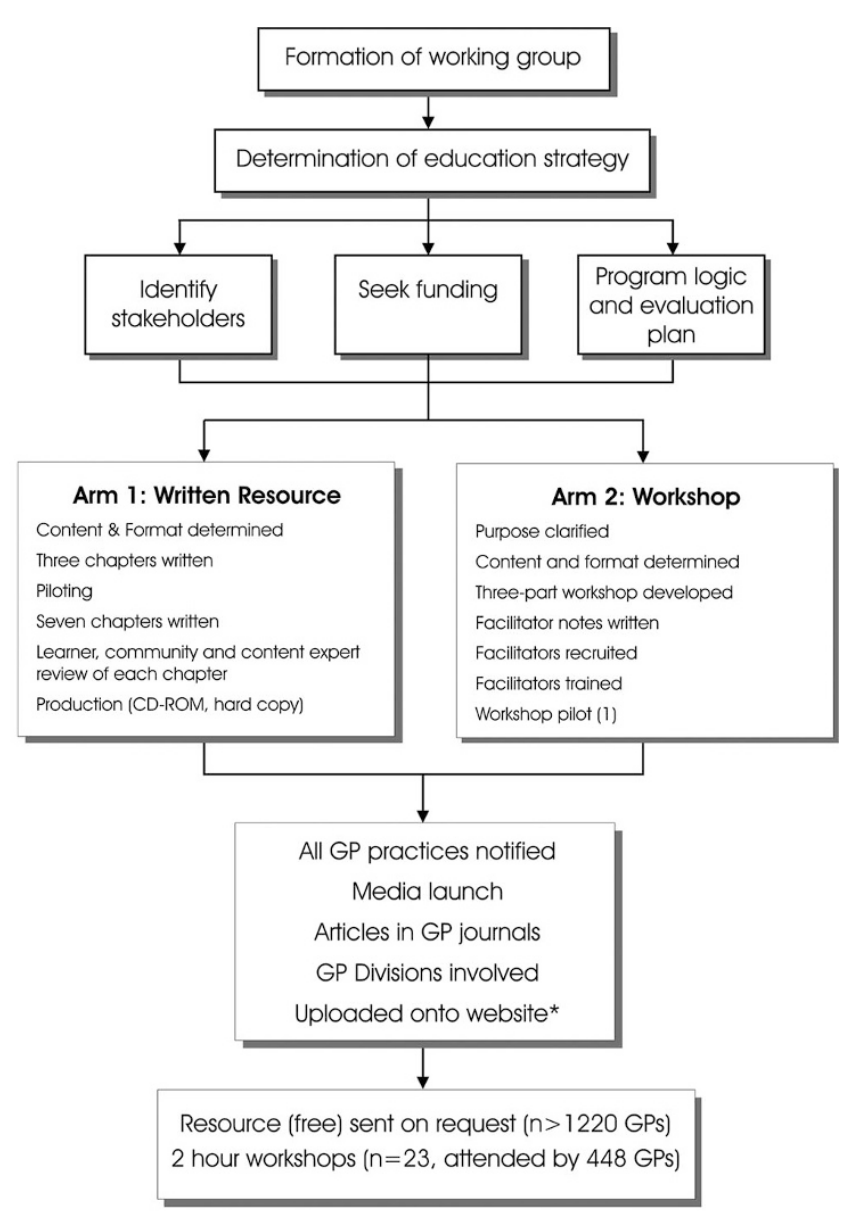

*mww.genetichealthvic.net. au

Fig. 2. Activities conducted in the development and delivery of "The Genetics File" education program. GP, general practitioner. velopment" phase of the program logic. At all points throughout this phase, as well as the previous and subsequent ones, a multidisciplinary approach was adopted with the involvement of individual GPs and GP professional bodies, as well as other stakeholders (Table 1). We believe this approach greatly strengthened the program because each group had a different perspective on the way the program aims could be achieved, causing vigorous discussion and resulting in a multifaceted, comprehensive but concise, pertinent, and user-friendly program. Again, involvement of the learner in program development adheres to adult learning theory.

In keeping with GP preferences, an enduring resource (the Resource Manual) was initially developed. The chapters of the manual were those identified in the needs assessment as priorities for the GPs, with the addition of one chapter on newborn screening at the request of one of the government funders, who was about to roll out a modified newborn screening program. GPs requested that genetic information be accessible on an "as-needed" basis and emphasized the need for it to be clear and concise. Thus, the design and content of the resource manual were intended to promote easy, sporadic access. Within each chapter, there are key points that are repeated and expanded in the background information section (see Appendix 1). Patient information sheets were also requested by those piloting the resource manual. A partnership was established with the Victorian Department of Human Services center responsible for public information (www.bettherhealthchannel.vic.gov.au), resulting in the updating of existing public information and development by this group of new information sheets that were then included at the end of each chapter.

The literature regarding the positive effect of enduring materials on changing practice is inconclusive. ${ }^{38}$ Therefore, an additional interactive component was developed to maximize the use of the resource manual: a workshop with the primary aim of familiarizing GPs with the manual. A secondary goal was to educate GPs at the workshops about genetics, specifically prenatal genetic testing, thalassemia, and hemochromatosis. $\dagger$ With the principles in mind of critical reflection, problem-centered and experiential learning underlying andragogy, workshops were designed around three scenarios (see Appendix 2). Questions were provided with directions to the relevant sections of the resource manual. Participants discussed the answers initially in small groups, and then key issues were raised by participants or the facilitators in large group discussion. This format allowed participating GPs to contribute their expertise and learn from others and develop familiarity with the manual.

\section{Program delivery}

The resource manual was made available, free and on request, to all 1900 General Practices in Victoria, with approximately 1220 GPs from at least 800 different practices requesting a copy. This strategy was adopted on the advice of GPs and

†Cancer Genetics Workshops were conducted as part of a separate program organized through the Cancer Council Victoria. 
Table 1

Involvement of general practitioners and others in the development and implementation of the program and evaluation

\begin{tabular}{|c|c|c|c|}
\hline Phase & Activity & GP involvement & Others involved \\
\hline \multirow[t]{4}{*}{ Whole program } & Stakeholder bodies & RACGP & MCRI \\
\hline & & GPEA & DHS \\
\hline & & & GHSV \\
\hline & & & UniMelb \\
\hline \multirow[t]{3}{*}{ Program development } & Project group & $\begin{array}{l}\text { GPs on resource project group } \\
\text { GP advising workshop format }\end{array}$ & $\begin{array}{l}\text { Genetic counselor } \\
\text { Genetics educator }\end{array}$ \\
\hline & Chapter review & $\begin{array}{l}\text { GP reviewers, GP educators, metropolitan } \\
\text { and rural GPs }\end{array}$ & $\begin{array}{l}\text { Genetic specialists } \\
\text { Content experts } \\
\text { Support groups } \\
\text { Laboratory scientists }\end{array}$ \\
\hline & Workshop & GP input & $\begin{array}{l}\text { Genetics educators } \\
\text { Genetic specialists }\end{array}$ \\
\hline \multirow[t]{3}{*}{ Implementation } & $\begin{array}{l}\text { Distribution of } \\
\text { resource }\end{array}$ & Advertising in GP journals & DHS mail-out \\
\hline & $\begin{array}{l}\text { Notification/location } \\
\text { of workshop }\end{array}$ & GP regional organizations & $\begin{array}{l}\text { Organized by Genetics Education Unit } \\
\text { (MCRI) }\end{array}$ \\
\hline & Facilitators & Each workshop had a GP facilitator & Genetic counselor \pm Genetics educator $(\mathrm{s})$ \\
\hline \multirow[t]{4}{*}{ Evaluation } & Strategy & Academic GPs & $\begin{array}{l}\text { Authors } \\
\text { Government funding bodies }\end{array}$ \\
\hline & Pilot resource manual & $25 \mathrm{GPs}$ & RACGP \\
\hline & Pilot workshop & $14 \mathrm{GPs}$ & \\
\hline & Summative & $448 \mathrm{GPs}$ & $\begin{array}{l}\text { Authors } \\
\text { Academics with relevant expertise }\end{array}$ \\
\hline
\end{tabular}

RACGP, Royal Australian College of General Practitioners; GPEA, General Practitioner Education Australia; MCRI, Murdoch Childrens Research Institute; DHS, Victorian Department of Human Services; GHSV, Genetic Health Services Victoria; UniMelb, The University of Melbourne; GP, general practitioner.

GP educators, who suggested that GPs would expect the manual to be free but, because they are inundated with free advertising material, may not recognize or value an unsolicited education resource. This also served to keep costs manageable. Consistent with the needs assessment, the manual was made available in all three of the preferred modes of delivery (CD-ROM, web-based, printed). The manual is presented in a format that allows additional information or updates to be included.

Despite documented interest by GPs in attending genetic education activities, ${ }^{39}$ the reality of delivering GP education programs is that attendance is often disappointing (GP Divisions, personal communication, 2003). In general, attendance at metropolitan workshops was higher than at rural/nonmetropolitan workshops, with an average of 22 attendees at the former compared with 17 at the latter. The involvement of regionally based GP Divisions, who are responsible for regional GP education activities, greatly facilitated attendance, with the highest numbers achieved when the program was held on a night routinely dedicated to CPD activities and when the regional division education officer was enthusiastic about the program and actively promoted it with division members. We could reliably anticipate that approximately one quarter of those who had registered for the program in advance would fail to attend, although this was improved by phone or fax contact with the registrants' practice on the day before the program.
Evenings with less than six registrants were canceled. This was a difficult decision because they were always in underserved rural areas where the practitioners had high workloads and large distances to travel; however, the cost of the program could not be justified for this small number.

The ideal number of attendees was found to be between 20 and $30 \mathrm{GPs}$, which provided a range of views and experiences but was not too large to facilitate. It was notable that issues raised by GPs were different at each workshop and that the contrast between metropolitan and nonmetropolitan services was particularly stark, reflecting geographic service provision issues. In this regard, as well as many others, the GP cofacilitators (often local) proved useful and provided input and a degree of credibility that genetic specialists alone would not have achieved. It was particularly satisfying that some workshop participants offered to be involved and facilitated some subsequent workshops.

\section{Evaluation strategy}

In accordance with evaluation theory, the program was subject to formal evaluation at each phase of its life cycle. The phases, evaluation questions, and success criteria are documented in Table 2. As part of the formative stage, a needs assessment was conducted and the program (early chapters of the resource manual and the entire workshop) was piloted. 
Table 2

Examples of evaluation questions and success criteria in the Genetics File program

\begin{tabular}{|c|c|c|c|}
\hline Evaluation & Program phase & Evaluation questions & Success criteria \\
\hline $\begin{array}{l}\text { Formative: Needs } \\
\text { assessment }\end{array}$ & Development & $\begin{array}{l}\text { Is there a need for GP education in genetics? } \\
\text { If yes, what is this need? } \\
\text { If yes, what are GP preferences for content and format? }\end{array}$ & Documentation \\
\hline \multirow[t]{2}{*}{ Formative } & $\begin{array}{l}\text { Piloting: resource } \\
\text { manual }\end{array}$ & $\begin{array}{l}\text { Is the information relevant? } \\
\text { Is the information clearly presented? }\end{array}$ & Incorporation of changes \\
\hline & Piloting: workshop & $\begin{array}{l}\text { Is the information relevant? } \\
\text { Is the information clearly presented? } \\
\text { Is the presentation engaging? } \\
\text { Are there areas where knowledge scores are relatively poor? }\end{array}$ & Incorporation of changes \\
\hline Process & Implementation & $\begin{array}{l}\text { Is the attendance rate adequate? What factors seem to be contributing to } \\
\text { attendance? } \\
\text { Does the facilitators' guide contain the answers to questions raised in } \\
\text { each workshop? }\end{array}$ & \\
\hline \multirow[t]{2}{*}{ Summative } & End of program & $\begin{array}{l}\text { Does the combined program improve knowledge, attitudes, and theoretic } \\
\text { behavior in relation to genetics? }\end{array}$ & Significant improvement \\
\hline & & $\begin{array}{l}\text { Does attendance at an interactive workshop impact on GPs' awareness of } \\
\text { genetics relevant to their practice? }\end{array}$ & Significant difference \\
\hline
\end{tabular}

GP, general practitioner.

While the program was being conducted, feedback was obtained from workshop participants on the workshop and the resource. Pilot data were assessed, and the content of the workshop was modified where knowledge items scored poorly. The use of three lead facilitators ensured consistency as they debriefed together after each program and modified the facilitator's guide to include questions arising or to provide additional guidance.

The program also underwent summative evaluation. The most rigorous way to determine the impact of the resource manual would have been to conduct a randomized control trial; however, the funding bodies' priority was that the resource be made available to all GPs as soon as feasible. A randomized control trial was therefore not possible, and a pragmatic pretest/posttest design was instead adopted, a strategy commonly used in action research. Validated measures were used to assess knowledge, attitudes, and theoretic behavior before the workshop and at 1 and 6 months after attendance. Data on use of the resource by workshop attendees were also collected at the 6-month time-point and compared with feedback data from GPs who had only received the resource without attending a workshop. The results of this evaluation support the effectiveness of the application of adult learning theory in health professional education.

\section{CONCLUSIONS}

Educational strategies are just one method of influencing clinical behavior. ${ }^{40}$ Nonetheless, they are a potentially important component of implementation of genomic and genetic medicine. Stein ${ }^{41}$ describes four elements essential for any effective learning program: identified learning needs of the specified audience, clear goals and objectives, relevant learning methods, and a systematic effort to evaluate. The theoretic ap- proach presented in this article encompasses these elements and draws on three distinct theories: program logic modeling, adult learning theory, and evaluation theory. The resulting framework can be applied to the development and implementation of genetics education programs. The utility of the framework has been demonstrated in the development, delivery, and evaluation of "The Genetics File" education program for GPs.

\section{ACKNOWLEDGMENTS}

This program could not have been conducted without the financial support of the Victorian Department of Human Services, the Collaborative Research Centre for the Discovery of Common Human Diseases, and Biotechnology Australia/the Commonwealth Government of Australia. We are grateful to the many people who provided help and insight throughout: the peer-reviewers of the content of the resource, the facilitators of the workshops, and, in particular, Dr. Jenny Newstead, Michael Batchelor, Tarli Bogtstra, Dr. Denise Findlay, Jane Wallace, and Lydia Gaffney. Jennifer Livingston provided helpful comments on the article, and Yasmin Bylstra assisted with literature searches.

\section{References}

1. National Coalition for Health Professional Education in Genetics, 1996. http://www. nchpeg.org/. Accessed 31 January 2007.

2. Burton $\mathrm{H}$. Addressing genetics, delivering health. A strategy for advancing the dissemination and application of genetics knowledge throughout our health professions. London, UK: The Wellcome Trust and Department of Health, 2003.

3. Godard B, Kaariainen H, Kristoffersson U, Tranebjaerg L, et al. Provision of genetic services in Europe: current practices and issues. Eur J Hum Genet 2003;11(Suppl 2):S13-S48.

4. Australian Law Reform Commission/Australian Health Ethics Committee. Essentially yours: the protection of human genetic information in Australia. Sydney: Commonwealth of Australia, 2003.

5. Kershner MA, Hammond EA, Donnenfeld AE. Knowledge of genetics among residents in obstetrics and gynaecology. Am J Hum Genet 1993;53:1356-1358. 
6. Kirk M. Genetics, ethics and education: considering the issues for nurses and midwives. Nurs Ethics 2000;7:215-226.

7. Bankhead C, Emery J, Qureshi N, Campbell H, et al. New developments in genetics-knowledge, attitudes and information needs of practice nurses. Fam Pract 2001;18:475-486.

8. Metcalfe S, Hurworth R, Robins R, Newstead J. The need for a genetics education program for general practitioners in Victoria. Am J Hum Genet 2000;67:209.

9. Metcalfe S, Hurworth R, Newstead J, Robins R. Needs assessment study of genetics education for general practitioners in Australia. Genet Med 2002;4:71-77.

10. Burke S, Kirk M. Genetics education in the nursing profession: literature review. J Adv Nurs 2006;54:228-237.

11. Burke S, Bedward J, Thomas HJ, Farndon P. Genetic education for non-genetics SpRs: a needs analysis. Birmingham, AL: The University of Birmingham, 2005.

12. National Coalition for Health Professional Education in Genetics. Core competencies in genetics essential for all health-care professionals. http://www.nchpeg.org/ core/core.asp. Updated for 2005. Accessed February 8, 2007.

13. Kirk M, McDonald K, Anstey S, Longley M. Fit for practice in the genetics era: a competence based education framework for nurses, midwives and health visitors. South Wales, UK: Genomics Policy Unit, University of Glamorgan, 2003.

14. Blazer KR, Grant M, Sand SR, MacDonald DJ, et al. Development of a cancer genetics education program for clinicians. J Cancer Educ 2002;17:69-73.

15. Blazer KR, Grant M, Sand SR, MacDonald DJ, et al. Effects of a cancer genetics education programme on clinician knowledge and practice. J Med Genet 2004;41: $518-522$.

16. Gaff C, Aittomaki K, Williamson R. Oncology nurse training in cancer genetics. J Med Genet 2001;38:691-695.

17. McAllister M, O’Malley K, Hopwood P, Kerr B, et al. Management of women with a family history of breast cancer in the North West Region of England: training for implementing a vision of the future. J Med Genet 2002;39:531-535.

18. Piniewski-Bond J, Celestino PB, Mahoney MC, Farrell CD, et al. A cancer genetics education campaign: delivering parallel messages to clinicians and the public. J Cancer Educ 2003;18:96-99.

19. Watson E, Clements A, Lucassen A, Yudkin P, et al. Education improves general practitioner (GP) management of familial breast/ovarian cancer: findings from a cluster randomised controlled trial. J Med Genet 2002;39:779-781.

20. Watson E, Clements A, Yudkin P, Rose P, et al. Evaluation of the impact of two educational interventions on GP management of familial breast/ovarian cancer cases: a cluster randomised controlled trial. Br J Gen Pract 2001;51:817-821.

21. Kolb SE, Aguilar MC, Dinenberg M, Kaye CI. Genetics education for primary care providers in community health settings. J Community Health 1999;24:45-59.

22. Prows CA, Johnson N, Hetteberg C, Latta KK. Genetics program for nursing faculty: nursing school curriculum outcomes. Am J Hum Genet 2000;67:207.

23. National Coalition for Health Professional Education in Genetics. http://www. nchpeg.org/clearinghouse.asp. Accessed 12 September 2006.

24. Haga SB. Teaching resources for genetics. Nat Rev Genet 2006;7:223-229.
25. Burton H, Zimmern R. Education in the genetics era: genetics education for health professionals_-an essential component of genetics policy. Med Educ 2005;39:243244.

26. Funnell S. Program logic: an adaptable tool for designing and evaluating programs. Evaluation News and Comment 1997;6:5-17.

27. Quinn F. The principles and practice of nurse education, 4th ed. Cheltenham: Thornes, 2000

28. Knowles M. Andragogy. An emerging technology for adult learning. In: Boundarie of adult learning. Edwards R, Hanson A, Raggatt P, editors. London: Routledge, 1996:82-98.

29. Ballou R, Bowers D, Boyatzis RE, Kolb DA. Fellowship in lifelong learning: an executive development program for advanced professionals. J Management Ed 1999; 23:338-354.

30. Brookfield SD. Adult learning: an overview. In: Tuinjman AC, editor. Internationa encyclopedia of adult education and training, 2nd ed. Oxford: Pergamon, 1996:375380 .

31. Knowles MS. Self-directed learning: a guide for learners and teachers. Englewood Cliffs, NJ: Cambridge Adult Education, 1975.

32. Hinchcliff S. Lifelong learning in context. In: Continuing professional development in nursing: a guide for practitioners and educators. Quinn F, editor. Cheltenham: Nelson Thornes Ltd, 1998:34-58.

33. Bickman L. Using program theory in evaluation. New directions in program evaluation. San Francisco: Jossey-Bass, 1987.

34. Rossi PH, Freeman HE, Lipsey MW. Evaluation: a systematic approach, 6th ed. Thousand Oaks, CA: Sage, 1999.

35. Wholey JS, Hatry HP, Newcomer KE. Handbook of practical program evaluation. San Francisco: John Wiley \& Sons, 2004

36. Ovretveit J. Planning and managing an evaluation (Chapter 9). In: Evaluating health interventions: an introduction to evaluation of health treatments, services, policies and organizational interventions. Buckingham and Philadelphia: Open University Press, 1998:158-180.

37. Hawthorne G. Introduction to health program evaluation. West Heidelberg: Centre for Health Program Evaluation, 2000.

38. Davis DA, Thomson MA, Oxman AD, Haynes RB. Changing physician performance. A systematic review of the effect of continuing medical education strategies. JAMA 1995;274:700-705.

39. McCann S, Macauley D, Barnett Y. Genetics and genetic testing: are GPs likely to attend training courses? J Cancer Educ 2004;19:225-226.

40. Smith F, Singleton A, Hilton S. General practitioners' continuing education: a review of policies, strategies and effectiveness, and their implications for the future. $\mathrm{Br}$ J Gen Pract 1998;48:1689-1695.

41. Stein LS. The effectiveness of continuing medical education: eight research reports. J Med Educ 1981;56:103-110. 